\title{
Community based Asian agrifuture: how it can be achieved
}

\author{
Nobutaka Ito $^{1^{*}}$ \\ ${ }^{1}$ Chiang Mai University, Faculty of Engineering, Muang, Chiang Mai, 50200, Thailand
}

\begin{abstract}
Asia is one of the most productive agricultural regions in the world, however the quality control of agricultural food products should be severely and strictly managed from the view point of food security and safety due to the increase of food feeding demand to cover the drastic and rapidly increase of world human population in recent years. In this paper the current status of Asian agriculture is overviewed first, then the Asian agrifuture is discussed and proposed from the community based viewpoint how it should / can be promoted and achieved.
\end{abstract}

\section{Introduction}

The followings show the summarized overview of Asian agriculture. ASEAN Economic Community was established in December 2015. More than $60 \%$ of world population is in Asia. Rice is cultivated in most of Asian countries. Most of the Asian countries are still relying on the economy from agricultural production more or less. Almost $40 \%$ of wheat is produced in Asia. consisting of People's Republic of China, 17\%, India, 13\%, Pakistan, 3\% and others. (Source: USDA [PS\&D] October 2017.

The following three tables, and one figure provide the overview the further basic data of the current status of Asian agriculture in the world. It can be obviously found from Table 1 that Asia has a little bit more than $30 \%$ of the world cultivated farming area which is one of the reasons why Asia is always listed in the top ranking of agricultural production. Table 2 shows the world cereal production in which only three Asian countries of China, India and Thailand are producing almost equal to the total production of USA and EU even though both of China and India must produce mainly for domestic consumption for feeding their own people not to export. Figure. 1 shows the major cereal products trading percentage of rice, corn, wheat and soybean. Especially for rice, it is produced a little bit less than 500 million tons in the world, however more than $90 \%$ of them are produced in Asia, therefore it can be said that rice is one of the most important staple food crops in Asia. Table 3 shows the farming scale per farmer (one family of farmer) for various countries in the world. It is also very clear to see how Asian farmer is engaged with small scale farming compared to the others such as USA, Australia, Canada, France, England and EU.

* Corresponding author: ito@eng.cmu.ac.th 
Table 1. World cultivated farming area. production.

(unit:\%)

\begin{tabular}{|l|c|}
\hline World Region & Cultivate farming area (\%) \\
\hline Asia & $31 \%$ \\
\hline N. America & $16 \%$ \\
\hline Africa & $14 \%$ \\
\hline Europe & $10 \%$ \\
\hline L. America & $8 \%$ \\
\hline Oceania & $4 \%$ \\
\hline Others & $17 \%$ \\
\hline Total & $100 \%$ \\
\hline
\end{tabular}

Table 3. Farming scale (ha) / farmer.

\begin{tabular}{|c|c|c|}
\hline COUNTRY & 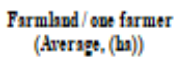 & $\begin{array}{c}\text { SPRCIFIC } \\
\text { PARMING SCALP }\end{array}$ \\
\hline Japan & 2.3 ba & 1 \\
\hline South Koren & $1.5 \mathrm{ba}$ & 0.6 \\
\hline Thniland & $3.7 \mathrm{ba}$ & 1.6 \\
\hline USA & $170.0 \mathrm{han}$ & 73.3 \\
\hline Australin & $3024.8 \mathrm{bn}$ & 1303.8 \\
\hline Caunda & $315.0 \mathrm{hn}$ & 135.8 \\
\hline Frauce & $53.8 \mathrm{ba}$ & 23.2 \\
\hline Euglaud & $84.0 \mathrm{ba}$ & 36.2 \\
\hline $\mathrm{EU}$ & $14.3 \mathrm{ba}$ & 6.2 \\
\hline
\end{tabular}

Fig. 1. Trading ratio of major agricultural products (unit: $1,000 \mathrm{t}$ ).

Notice: Above shown three Tables and Figure. 1 were processed by modifying the original data reported from FAO in 2006.

\section{Food production}

Asian nation self-sufficiency of cereal food (rice, wheat, corn etc.) which can be defined by the ratio of consumption to the production of food mainly expressed on calorie based. Some of them are shown respectively for Thailand: $166 \%$, Laos: $122 \%$, Vietnam: $117 \%$ and Japan $40 \%$. Thailand and Vietnam are the big agricultural countries producing 30 million tons of cereals per year. Laos is producing 3.81 million tons of cereals enough to feed their people. Among 177 countries in the world, Thailand is ranked in 7th, Laos is ranked in 19th and Vietnam is ranked in 21 st respectively in the world. Argentina is ranked at the top in the world for the food self-sufficiency at $306 \%$. China is ranked in the top of cereal production and her self sufficiency is $102 \%$, which means most of them are for domestic consumption to feed their own people. Therefore she is ranked in 31st in the world for food self-sufficiency. India is ranked in 29 th and food sufficiency is $105 \%$. Population in India is second to China. Food sufficiency for South Korea, Malaysia and Japan are almost 25 to $40 \%$ as mentioned above. Food production should be secured from the viewpoints of strengthening agriculture and its competitiveness. It may be achieved by the highly mechanized advanced value adding technology application to the actual farming site for extension. How it can be achieved successfully and completely is the key issue. The 
method of solving the issue and the process to follow are shown for further discussion of the project concept.

\subsection{Problems and solutions}

Asian agriculture can be characterized as the following problems and the conditions to satisfy for solving them: 1) Small scale, 2) Family labor, 3) Low income, 4) Heavy physical work and 5) Working poor. On the other hand the conditions to satisfy for promoting agriculture are shown below. Agricultural products should be 1) competitive in the world market, 2) High quality control and management of the products should be secured including safety and value adding and 3) Price of the products should be reasonable enough to make it competitive. Food security consists of the following four factors of 2QSL, which means enough 1) Quantity, 2) Quality, 3) Safety and 4) Liability). Let us think what and how we should do for achieving the goal of Asian agrifuture. It must be done not only to improve Asian agriculture, but also to make Asia one of the world food pantries.

\subsection{Method of income increase}

One of the methods of income increase can be achieved comparatively easier as it can be seen in Japan's case. That is to provide the additional job to let them be for part-time farmer. The ratio of the part-time farmer to full time farmer is $85 \%$ to $15 \%$ in Japan. Parttime farmer is rich enough to buy farm machinery individually for promoting the mechanization in addition to take care of family and education of children, therefore the original small scale farmland can be used mainly for domestic family consumption of food, not for earning money from the products selling. Additional merit of shifting small scale farmers to part-time farmers promoted the automation of agricultural machinery because most of them were small scale professional farmers and they needed automated machines more. One time the central government of Japan tried to push the industry to develop simple machines equipped without those automatic control functions, however both of industries and farmers couldn't accept those machines, because part-time farmers are rich enough to buy the automated machines in spite of expensive price. Even for industries they were welcome those part-time farmers if they can buy those expensive ones actively. It means no farmers want to buy such a low functional machine because of cheaper price only. Increasing the number of part-time farmers could solve the farmer's low income problem, however nothing could be done for promoting the agriculture at all.

\subsection{Answer for income increase and agriculture promotion issues}

The other way is to solve both problems of income increase and promotion of agriculture together is the scale up of farming per one farmer (or one family). The low income is caused by the small scale farming, therefore the farming scale up can improve and solve both problems together, however it looks difficult to do it quickly and takes time even if it could be done. Furthermore the majority of the farmers are too much aged and impossible to accept such a highly innovated smart agriculture due to the lack of knowledge and no next era young generation successor grown up. Referring to Table 3 showing the specific average farming scale ratio compared with the case of Japan is one, owned per one farmer for various countries, it can be found that other countries are extremely higher almost 20 to 1000 times than Asians. Considering the current level of agricultural mechanization, it looks for Asia almost impossible to make Asian agriculture competitive with the other countries. In parallel with the scale up of farming, the new project should be launched 
together focusing on the next era young generation farmer should be grown up who should be highly educated and qualified enough to understand apply the highly innovated technology even for transferring those technologies to the following next era too. The author named this project as FFA, Future Farmer of Asia growing project, Trainees are accepted based on the application from ASEAN member countries not only from Thailand, but also from the other member countries. Further details of program content is introduced and explained in the section of Asia Food Project and Agri Techno Farm Initiative later.

\subsection{Additional answer for solving the problems}

The conventional and traditional farming is essentially based on the farmland soil, however the green house based farming is now getting popular due to no need of farmland and soil, but hydroponics instead in addition to the merits of clean and automatic full control of environment while growing of target crop. The artificially made crop cultivation program can make it possible to secure the stable yield and multiple cropping per unit period of growing season. Additional merits of type of farming can be found as follows: 1) Anybody can join easily to this farming business even for the handicapped and disabled person, 2) Light labor forces under clean environment, 3) Higher probability of stable yield by artificially prepared cultivation program, 4) Fresh and safe products supply timely on demand etc. One of the problems is the possibility of mass production of main staple food like cereals such as rice, wheat, corn, soybean etc. to cover the rapidly increasing human population. The merit of applying this green factory type of farming can be found in special area such as North Africa and Middle East mostly covered area with desert but without cultivated farmland. They really need fresh, clean and safe food products. What about the possibility of growing main staple food crop in the green factory? If possible, a short plant rice variety with rice grain only without long length of straw and stem may be developed and experimentally tested for growing.

\section{Strategic policy for Asian agrifuture}

\subsection{Asian agriculture growth strategy}

Figure 2 shows the growth strategy and the process to follow. As already mentioned above the farming population should be reduced and the small scale farmland should be collected to expand the farming scale. As far as the farmers stay on small scale farming, they can't escape away from working poor under less income and have no hopeful future. The strategic policy should show the direction to go, but not to force the farmers to follow. The final decision must be made depending on the individual farmers which way they want to make choices such as to change the job completely to the other industries, to become a big scale farmer, or to keep staying on farm as small scale farmer as the part-time farmer. Some activity must be done actively for further promotion and improvement of agriculture. Recommendation, suggestion and follow-up support should be prepared and done to the farmers who are wishing to change the current situation. The central government should encourage the young generation to apply actively to be the FFA Future Farmer of Asia program by preparing the training center in which the six programs are offered and installed under the name of Asia Techno Farm Initiative. 


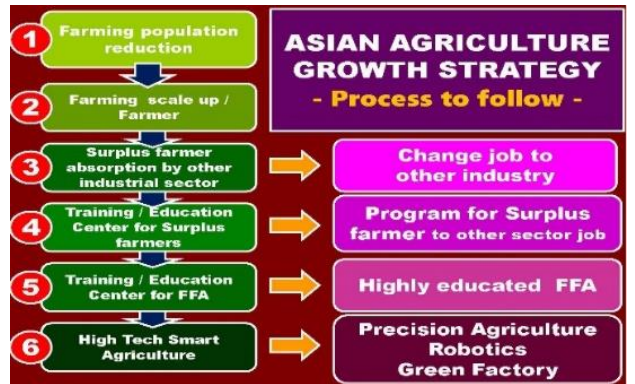

Fig. 2. Asian Agriculture Growth Strategy.

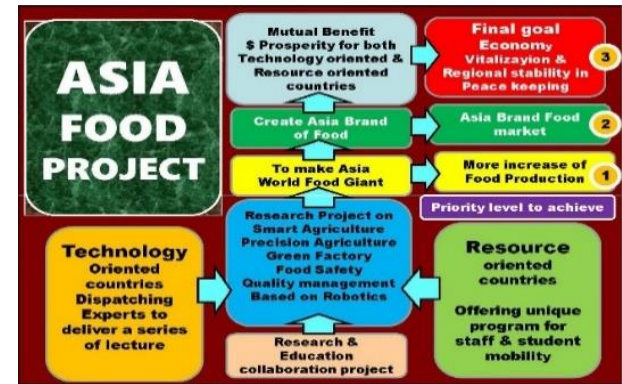

Fig. 3. Schematic view of Asia Food Project and main concept and process to follow and achieve the final goal of community based Agro-economic promotion and mutual prosperity between ASEAN andASEAN plus 3 countries.

\subsection{Asia food project}

There can be seen two kinds of countries in Asia, named ASEAN Economic Community consisting of ten member countries and ASEAN plus 3 countries including China, Japan and South Korea. ASEAN Community consists of agricultural countries relying on a huge amount of agricultural production more or less, therefore they can be categorized as the resource oriented countries. On the other hand ASEAN plus three are categorized as the technology oriented ones due to less amount of resources production. The main concept of Asia Food Project is to promote and make Asian economy sustainable based on the joint collaboration between the resource oriented and the technology oriented countries. They need resources and technologies mutually for further development and promotion of Asian economy in addition to the regional peace keeping. The process to the final goal should be followed and achieved along the priority number from one to three in order as shown in Figure 3. They are 1) To make Asia a world food pantry by more increase of quality controlled safe food production and supply, 2) To develop and create an original Asia brand food (product) market and 3) To achieve and maintain the Asian economic promotion stably and vitalization enough to contribute to the regional peace keeping. The mutual transfer relationship between the resources oriented and technology oriented countries can be sustainable for ASEAN Economic Community development.

\subsection{Asia techno farm initiative}

Figure 4 shows the whole concept and its schematic diagram of Asia Techno Farm program consisting of mainly three organizations of 1) University as program organizer, 2) Government as budget provider for supporting and promoting the national project and 3) Industry closely related to the project and program. University offers the program content consisting of six divisions such as .

1) Global solutions: Global issues related to Food, Energy and Environment should be discussed and found the solution. Update information and knowledge can be taught.

2) Smart agriculture: Precision agriculture: Agricultural mobile robot and related control and management technology are taught including sensor, actuator and peripheral control devices etc. 
3) Smart agriculture: Robotics in agriculture use: Basic knowledge and skill related to robotic machine control are taught including sensor, actuator and peripheral control devices etc

4) Smart agriculture: Green factory: Environment control, image processing, sensing, data acquisition skill etc. are taught

5) Special education: Special skill and knowledge necessary to provide opportunity and give advices to the farmers wishing to change the job.

6) Social service: Recommendation / Introduction letter and Official documents such as certificate, diploma and approval can be issued in addition to the negotiation to the different organization and industry for the surplus farmer wishing to change the job.

Related industries to join the program or project are requested to provide the machines for educational material and send one technician with free of charge for taking care of the maintenance and repair of the machines provided in case of the trouble. Some lecture delivery related to the machine maintenance and spare parts supply may be possibly requested especially for the old model secondhand machines if necessary.

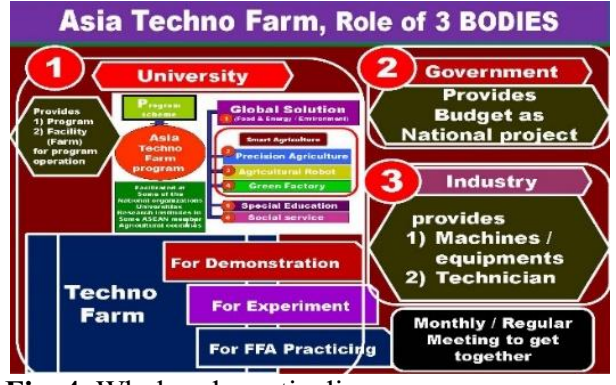

Fig. 4. Whole schematic diagram of Asia techno farm initiative.

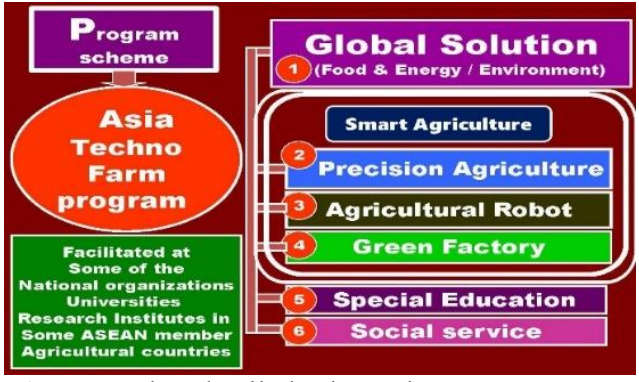

Fig. 5. Further detailed schematic program content.

Asia Techno Farm Initiative program accepts trainee participants from ASEAN member countries. Applicants should be qualified enough to communicate in English. Academic background should be higher than undergraduate program level. The main major of the trainee participants which division he or she makes a choice depends on the individual expertise and career to be considered in case by case. The program can be operated for almost six months equal to one season of crop cultivation. The participants should be involved in the actual farming at least one season for practical experience. Three farms are prepared for the newly developed technology demonstration, experimental farm and FFA trainee participants crop cultivation practice. The industry participation and its support and cooperation to program operation can be highly considered. The strong recommendation can be made to the trainee participants if they want to buy the related machines from industry participated to the program after the successful completion of the program.

\subsection{FFA (Future Farmers of Asia) growing program}

FFA Smart Agriculture Training program should be implemented at farm prepared by the university appointed as the project organizer. The program is roughly shown as below. (See Figure 5)

Length of program operation: 6 months

Contents of the program involves the following six divisions

Smart agriculture includes the following three divisions. They are Precision Agriculture, Robotics and Green Factory. Emerging Technology lectures available for agriculture should 
be offered and provided. Data acquisition and processing can be taught such as ,Sensing, Monitoring, Data Gathering, Processing

For practical skill up, the practice of one season target crop cultivation is requested for experience and practical skill up learning. The official qualification of the program participation can be made based on the final report submission \& presentation in addition to the certificate issue \& its grant.FFA program participants can be accepted almost $10-15$ per one time program operation. They can be accepted mainly from ASEAN countries. The invited lecturers are requested to stay at least one week per one time visit and deliver a series of lecture for 4 days. In addition the other 2 days should be spent for the visit on site What is the reason why this is requested for the invited lecturer to follow? The main reason is to know more 1) Asian Agriculture, 2) To have more communication with trainees and 3) Further improvement of English communication for promoting mutual friendship between lecturers and trainees.

After the successful completion of program, 2 weeks study tour may be offered and scheduled for the trainees to visit the invited lecturer's laboratory.

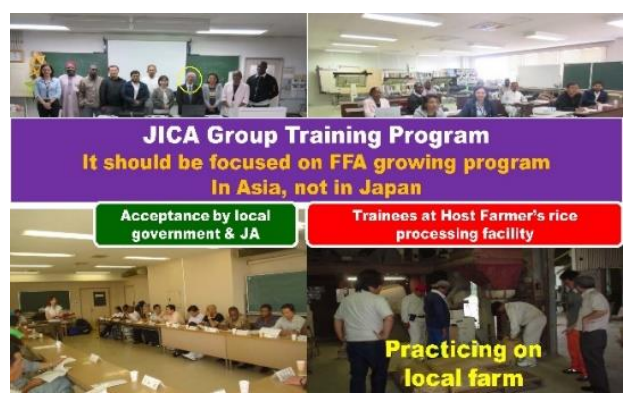

Fig. 6. Group training program offered to JICA and accepted by NPO.

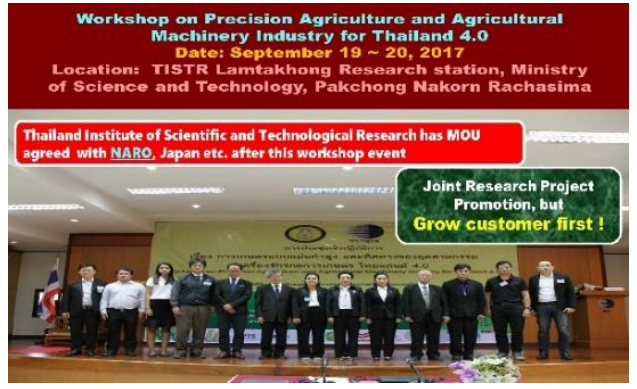

Fig. 7. The first workshop on precision agriculture organized by Ministry of Science and Technology, Thailand.

Technology to be transferred from "Supply" side should be "Appropriate Technology" which can be defined to satisfy the following conditions and it should be enough to cover a huge scale farming_mainly based on precision agriculture in smart agriculture.

1) Technologically feasible.

2) Socially acceptable.

\section{Conclusions}

Many factors must be considered in the promotion of Asian agriculture, however looking at the current status of agricultural mechanization in Asia, the implementation of agricultural reforms at the community based level is more important and meaningful than supporting individual farmers. At present, it looks difficult for the farmers to accept high-tech represented by precision agriculture for example. The first priority is to create the demands and needs of the customers (farmers) who can accept such high-tech machines and equipments. FFA (Future Farmers of Asia) growing program should be highly considered as the first priority issue. The market should be developed actively for those trainees to work with joy.

The following is the summarized conclusion derived from the discussion development in this paper. 
1) ICT \& IOT based Smart Agriculture are paving the way for high-tech agricultural mechanization, however the speed of technology development and innovation are evolving day by day.

2) These technologies are still under developing and innovating, but constantly and stably day by day. However............

3) To whom and How do we transfer those technologies?

4) There are many small scale farmers in Asia, but "None of them" can understand and accept those high-tech mechanization now due to the lack of knowledge and economic power, aging and no young successor wishing to be a farmer.

5) The right answer is the strong suggestion to "Make customers first" for agri-business promotion of The situation of Asian agriculture can be neither improved nor changed unless no action could be started and taken immediately not to be too late.

The author would like to express his sincere appreciation to DLG International, Germany, Projektteam AGRITECHNICA ASIA - Horti ASIA | Project Team AGRITECHNICA ASIA - Horti ASIADLG International GmbH Eschborner Landstraße 12260489 Frankfurt am Main

\section{References}

1. Nobutaka Ito, Asia Techno Farm, in Proceedings of The International Conference of Building of Food Sovereignty through a Sustainable Agriculture: Challenge of Climate Change and Global Economic Community, University of Jember (UNEJ), East Java, Indonesia, August 1st $\sim 3 \mathrm{rd}, 2017$ Indonesia (2017)

2. Nobutaka Ito, Asia Techno Farm Initiative, in Proceedings of Thai Society of Agricultural Engineering, Impact Arena, September 9 10, 2017, Bangkok, Thailand (2017)

3. Nobutaka Ito, How Asian agriculture should be changed and promoted for Regional Community Development, (Keynote speech), in Proceedings of The International Conference on Agricultural and Bio-system Engineering, Nong Lam University,Vietnam, December 19 20, 2017, Hochiminh, Vietnam (2017)

4. Noutaka Ito, FFA (Future Farmers of Asia) growing program, in Proceedings of The 11th TSAE International Conference, 26 27 April, Chulaborn International Convention Center (Wora Wara Hua Hin Hotel \& Convention) Hua Hin, Prachuap Khin Khon, Thailand (2018)

5. Nobutaka Ito, Asian Agriculture Growth Strategy, published in the Journal of Applied Mechanics and Materials (ISSN print 1660-9336)

Da Nang, Vietnam (2018)

Notice: Papers listed above were presented by the author or published in recent years in the Proceeding of the International Conference / Symposium / Workshop related to Asian agriculture and its promotion based on the proposal how the technology transfer and human resources development should be made to achieve the final goal of Win - Win relationship between both of the resource oriented ASEAN and technology oriented ASEAN plus 3 countries. 